\title{
Editorial
}

\section{Empathy, imperturbability and good doctors and quality drugs}

\author{
Journal of the Ceylon College of Physicians, 2015, 46, 1
}

William Osler in 1889 said "In the physician or surgeon no quality takes rank with imperturbability. The physician who has the misfortune to be without it, who betrays indecision and worry, and who shows that he is flustered and flurried in ordinary emergencies, loses rapidly the confidence of his patients." Is this at odds with today's modern medicine, the key words of today being empathy, compassion, and kindness? Excessive use of technology, the limited time available to see patients have made physicians of today strangers at the bedside. To overcome this phenomenon, communication skills, ethics, and the humanities have been included in the medical curriculum, in an attempt give the stranger a human face. So in the recent times the focus had been on developing skills of empathy in doctors.

Empathy is a complex multidimensional concept that has moral, cognitive, emotive, and behavioural components. It involves the ability to understand the patient's situation from his perspective and communicate that understanding in a helpful way. It is not to cry with your patient or family but to convey to them that you are attuned to their emotions and concerns. It does not require the doctor to have those feelings. Doctors who are empathic have a positive effect on the patient experience because they convey a genuine regard rather than the cool headed aloof doctors. Imperturbability is also an effective quality that doctors should have and a good doctor will have the skill to use the correct mix at the correct time. In this issue of the Journal an eminent lawyer writes on invitation on the societal view of physician empathy. It is useful reading to all of us so that we have a point of view, from the other side of the consultation desk.

Chairperson of the National Medicines Regulatory Authority writes about the birth of the NMRA and the hurdles it faced and it is more likely it will face many more obstacles in implementation. There are progressive concepts as well as people friendly concepts in the act and the concern of many are that whether it is being used only as a tool for political gain. It is my opinion that no act will work unless we can assure the quality of the generic drugs purchased. Users of the drugs, the doctors and the patients need to be confident of the product they use as being effective and safe. At present this is impossible. So the primary aim should be quality control and purchase of quality assured drugs and this would create a competitive market that would help in stabilizing prices and preventing unreasonable profit making by pharma. Flooding of the market with vitamins and other nonmedicinal products need to be curtailed. Promotion of expensive drugs with marginal and doubtful benefits too should be controlled as many patients spend their money unknowingly. Trying to implement policies that were conceptualized and were applicable almost half a century ago would result only in the failure of its implementation and its acceptance by the professionals who are the main stake holders.

\section{Saman B Gunatilake}

Co-Editor 